\title{
Digitalization of the Russian Economy as a National Goal
}

\author{
A.V. Savoskin*, A.V. Kurdyumov, V.A. Meshcheryagina, and M.N. Vilacheva \\ Ural State University of Economics, 620144 Yekaterinburg, Russia
}

\begin{abstract}
The gist of this article boils down to the legal conditions for the formation of a unified system of digitalization of the economy based on the improvement of normative regulation of the digital environment are considered; creation of information infrastructure of the economy; providing the digital economy with competent personnel; ensuring information security. The authors conclude that the state concept of "digital transformation" has not yet been implemented, but the first steps in this direction have been taken. Achieving the national goal of digitalizing the economy will entail the creation of a new legal framework for relations between citizens, business and the state, which is necessary (and even inevitable) due to the development of digital technologies.
\end{abstract}

\section{Introduction}

Digital technologies have long become the norm in modern life and are taken for granted. At the same time, the normative regulation of the digital sphere lags behind modern realities, and a targeted state policy on managing the digital sphere took shape only in 2018 in connection with the publication of the Decree of the President of the Russian Federation dated May 7, 2018 No. 204 "On national goals and strategic objectives of the development of the Russian Federation in period until 2024 ". It is indicative that it was this Decree that set the task of accelerating the introduction of digital technologies in the economy and social sphere, that is, it was about the digitalization of only two spheres of public life. In pursuance of this document, the Presidential Council for Strategic Development and National Projects on December 24, 2018 adopted a comprehensive National Program "Digital Economy of the Russian Federation".

At the same time, in 2020 the President of the Russian Federation adopted a new Decree of 21.07.2020 N 474 "On the national development goals of the Russian Federation for the period up to 2030" which replaced the national development goal of Russia "ensuring the accelerated introduction of digital technologies in the economy and social sphere" the broad goal of "digital transformation". This goal is no longer limited only to social and economic spheres and includes such target indicators as: increasing the share of mass socially significant services available in electronic form to $95 \%$; increase in the share of households that are provided with the possibility of broadband access to the Internet, up to $97 \%$; a

\footnotetext{
${ }^{*}$ Corresponding author: savoskinav@yandex.ru
} 
multiple increase in investments in domestic solutions in the field of information technology.

Thus, we see, on the one hand, the expansion of the state's approach to regulating digital relations in Russia, and on the other hand, the preservation of the task of digitalizing the economy. Taking into account the relative vagueness of the term "digitalization" (and related phrases), it is highly desirable to understand how the state intends to ensure this very "digitalization" and what it sees as the end result of its efforts.

Analysis of normative acts (first of all, Decrees of the President of the Russian Federation, Resolutions of the Government of the Russian Federation, Orders of the Ministry of Digital Affairs of Russia and acts of the Russian Federation, decisions of the Council under the President of Russia for Strategic Development and National Projects, acts of the Commission on Digital Development, the use of information technologies to improve the quality of life and conditions for doing business activities, acts of other bodies), as well as information on the official websites of government bodies, the following areas of digital transformation of the economy in Russia can be identified: improvement (creation) of regulatory regulation of the digital environment; creation of information infrastructure of the economy; training of personnel for the digital economy; ensuring information security; introduction of digital technologies, including in the field of public administration. At the end of 2019, the federal project "Artificial Intelligence" was added to these areas (Decree of the President of the Russian Federation of 10.10.2019 N 490 "On the development of artificial intelligence in the Russian Federation").

It is obvious that the existing regulatory legal framework governing the transformation of the digital economy of states, including Russia, requires improvement, which, in particular, scientists point out $[2,4,5]$.

It would be incorrect to argue that the listed areas fully correspond to general theoretical views on the economy or exhaust domestic and world practices of its digitalization, but this is exactly how at the current moment (end of 2020) these areas are indicated in the legislation and documents of strategic planning of Russia and it is according to them that systematic administrative - management work (which, by the way, has already managed to give its positive results). Therefore we will analyze each of these areas of digitalization of the economy in more detail.

\section{Materials and Methods}

The methodological basis of the research is general scientific research methods: analysis, synthesis, deduction and induction, abstraction, structural and functional method. When studying the normative legal regulation of the digitalization of the economy, the authors operated with special methods of economics and jurisprudence: formal legal, the method of legal construction; formal-logical, systemic, technical and legal analysis, statistical method, a method for determining economic links between the level of legal regulation and production indicators (for example, the digitalization of the agro-industrial complex).

\section{Results and Discussion}

The administrative and managerial activity of the state presupposes the implementation of its powers through various means, among which legal and economic regulation are, of course, of fundamental importance, being in close relationship with each other.

Therefore, the effectiveness of public administration of the digitalization of the economy (established by the national strategy and other regulations) will have a positive trend only with a comprehensive analysis of legislation and specific economic indicators of 
the enterprise's liquidity, taking into account the phased introduction of digitalization into its activities.

Taking into account these features, the following components of the digitalization of the economy will be considered in more detail: improving the regulatory framework of the digital environment; creation of information infrastructure of the economy (for example, the agro-industrial complex); providing the digital economy with competent personnel; ensuring information security.

\subsection{Improving the regulatory framework of the digital environment}

Implies several relatively multidirectional areas, among which the following should be highlighted.

Adoption of fundamentally new laws and regulations that ensure not only the regulation of the digital economy, but also the transition to digital civil circulation of goods and services. In Russia, legal conditions have already been created for the formation of a unified digital environment of trust, in particular: the status of certification centers has been unified; consolidated uniform requirements for a universal (unified) enhanced qualified digital signature; the possibilities and methods of automated remote identification of participants in digital relations have been expanded; legalized the status and procedure for civil circulation of digital financial assets (first of all, Federal Law of July 31, 2020 N 259FZ "On digital financial assets, digital currency and on amendments to certain legislative acts of the Russian Federation", which will enter into force on January 1, 2021 of the year).

At the same time, in order to expand the practice of using electronic civil circulation, the legislator should: determine which written transactions are permissible to be made in electronic form; formalize and unify the storage of electronic documents, including fixing the algorithm for creating, storing and using electronic images of paper documents. It is also expected to stimulate VAT payers providing IT services.

Improving the sphere of legal proceedings and notaries in order to develop the digital economy. To this end, it is planned to unify the rules for filing legal appeals of citizens (statements of claim and other procedural documents) in electronic form, as well as the rules for submitting evidence in electronic form; introduce the possibility of remote participation in court sessions; give an official status to electronic notary instruments (including legalizing notarial documents produced in electronic form, permitting remote execution of notarial actions, etc.).

Here I would like to note that the announced concept of "digital justice" has not yet been implemented, but the first steps in this direction have been made. So the opportunity to file electronic claims in courts of general jurisdiction appeared back in 2017 (arbitration courts have been accepting electronic materials since 2011). This opportunity has been implemented on the platform of GAS "Justice". In 2019, citizens and organizations have already sent 1.5 million documents in electronic form to courts of general jurisdiction. At present, the creation of a superserver on the platform of the state services website has been announced. At first glance, this is a logical continuation of previous measures to "digitalize" the judicial system. Such a superservice will combine several electronic services that are already available in the SAS "Justice". However, the main innovations should be remote participation in court sessions. In addition, the super service assumes the ability to automatically determine the jurisdiction of cases, receive all court notices in the personal account of the public services system, access the case materials in the personal account, as well as the calculation of the state fee and its payment directly on the public services portal. 


\subsection{The creation of the information infrastructure of the economy}

Requires significant material costs, which are covered primarily by the state budget or targeted investments. This is probably why the vast majority of events are still being planned.

Many scientists emphasize the conditioning of the ongoing processes by economic, political, social, cultural and academic motives $[5,6,7]$.

Among those already implemented, it can be noted: creation of a public network platform for the management of rights to the results of intellectual activity and means of individualization; development, commissioning and operation of the GIS "Federal portal of spatial data", which ensures the availability of information contained in the federal fund of spatial data, and the GIS "Unified electronic cartographic framework" (while its use by the authorities should increase from $13.9 \%$ to 2019 up to $100 \%$ in 2024); conditions were established and sources of financing for the project of the domestic Global Multifunctional Infocommunication Satellite System (GMISS) were found; in terms of "artificial intelligence" and "robotization" technologies, new services have been introduced in the USRR FGIS, etc. Also, the completion of a large number of scientifically based and economically calculated plans and concepts for building a digital infrastructure.

Among the key plans it is necessary to mention: provision of access to the Internet in all settlements with a population of over 250 (in total, it is planned to provide 13958 small settlements with wireless Internet by 2024); creation of secure single channels of audiovisual interaction of officials of all levels of government with each other, as well as with citizens and representatives of organizations; creation and promotion of the development of the state segment of the Internet (RSNet network); implementation of a control system for the provision of communication services in socially significant facilities; transition to the use of 5G / IMT-20 technology for data transmission (for this, even a separate Concept for the creation and development of 5G / IMT-2020 networks in the Russian Federation was adopted, approved by Order of the Ministry of Telecom and Mass Communications of Russia dated December 27, 2019 N 923); 100\% coverage of federal highways by radiotelephony by 2024; creation by 2021 of a unified state cloud platform and transfer of $70 \%$ of all information public resources to it by 2024; by 2024 creation of a system of data acquisition and processing centers dispersed over the territory of Russia and resistant to disasters (which should be created on the basis of domestic equipment); creation of the domestic web platform "Digital Earth", providing collection, processing, storage and use of Earth remote sensing data by 2022; by 2021, inventory, accounting and control of all types of energy resources of property state and monopoly complexes based on a digital platform; formation of the Smart City ecosystem, including the Smart City Solution Bank resource and IQ assessment for cities and digitalization of urban economy based on it by 2024; support for projects of small enterprises developing and implementing digital platforms and technologies aimed at developing information infrastructure ( however, only 35 projects in 2020 and 50 in 2021); creation and commissioning by the end of 2021 of an early warning system for computer attacks on the Russian telecommunications infrastructure.

Various aspects of the complex problem of development and digitalization of the agroindustrial complex of Russia at different levels of its formation at different times were considered in the works of Russian and foreign scientists $[9,6,11]$.

To implement the national development goal of the Russian Federation in the digital aspect, it is necessary to synchronize state and national programs. For example, in order to digitalize the economy of the agricultural sector, it is important to analyze and take into account the implementation of state support throughout the entire chain of agricultural production. 
It should be noted that many Russian and foreign scientists emphasize the need to form a comprehensive and full-fledged system of formal institutions (legal field) for the effective implementation of information and communication systems and the development of the digital economy, this is indicated in particular by $[11,12,13]$ and others.

The adopted subprogram "Creation and development of infrastructure in rural areas" of the state program of the Russian Federation "Comprehensive development of rural areas" (as amended by Resolution of the Government of the Russian Federation of October 17, 2019 N 1332), within the approved implementation timeline for 2020-2025, should take into account the goals of digital transformation agro-industrial complex.

It is important to note that not all regulatory legal acts regulating the agricultural sector contain a digital aspect in their tasks. So, in the Strategy for Sustainable Development of Rural Territories of the Russian Federation for the period up to 2030 (approved by the order of the Government of the Russian Federation dated 02.02.2015 N 151-r), the task of creating conditions for ensuring a stable improvement in the quality and standard of living of the rural population basically does not take into account the role of digitalization.

The Strategy for the Development of the Agroindustrial and Fisheries Complexes of the Russian Federation for the Period up to 2030 (approved by Order of the Government of the Russian Federation dated April 12, 2020 N 993-r) takes into account the need to ensure the accelerated introduction of digital technologies in the economy and social sphere.

The digital transformation of the economy of the agricultural industry requires tools for coordinating the subjects of the entire management system in a continuous mode, which are able to assess the level of digitalization by key indicators and compliance with target priorities, including timely adjustment of funding. This tool can serve as appropriate guidelines for the subjects of the agricultural industry developed and adopted by the relevant curator of the project or program.

\subsection{Providing the digital economy with competent personnel}

Is necessary primarily because, due to the development of digital technologies, work appears that was not even expected yesterday.

The authorities are faced with the task of developing such a model of human competencies in the digital economy, so that it includes the necessary set of key skills sufficient for effective not only professional, but also daily activities in the modern digital environment. Such a model should become an addition to the existing requirements laid down in educational programs and requirements for the implementation of professional activities.

To make it easier for every Russian to develop his digital competencies, it is planned to develop a personal profile of competencies and the trajectory of their development. The personal profile of competencies should become a kind of "passport", including knowledge, skills, abilities, competencies, accumulated experience and various achievements of a person, which will allow a person to analyze his personal competitiveness in the labor market, identify missing competencies, and plan their acquisition and development. Competency testing is possible not only through formal procedures (exams, tests, etc.), but also through other forms (participation in an accelerator or hackathon), which can be carried out by an independent operator.

Due to the rapid development of technology, the requirements for the knowledge and skills of specialists, many higher education programs become obsolete at the time of training. Therefore, it is planned to conduct pilot experiments in obtaining higher education for 2 years (by analogy with the Associate's degree, half-bachelc) within the framework of certain specialties of the digital economy. The acute shortage of specialists with digital competencies is also forcing accelerated training. 
The digitalization of the economy will inevitably entail greater automation of processes and a reduction in the number of jobs, which actualizes the issues of unemployment and puts the state in expanding opportunities for self-employment and entrepreneurship. It is no coincidence that one of the key target indicators for achieving the national development goals of Russia is designated as "an increase in the number of individual entrepreneurs and self-employed, up to 25 million people" (paragraph 6, subpara. "D", clause 2 of the Decree of the President of the Russian Federation of July 21, 2020 N 474 "On the national development goals of the Russian Federation for the period up to 2030".

\subsection{Provision of information security}

Was reflected even in the amendments to the Constitution of the Russian Federation in 2020 (with the addition of paragraph "m" of Article 71 of the Constitution of the Russian Federation), which indicates the highest priority of this area of activity.

Information security issues have been on the agenda for a long time. Therefore, Russia has already implemented a set of measures to analyze global trends in the development of information technology in the field of information security; an assessment of potential vulnerabilities, threats and risks of information security was carried out (primarily when using cloud, fog, quantum technologies, artificial intelligence and augmented reality systems; the stability, risks and threats to the safe functioning of a single telecommunication network, as well as elements of the Russian segment of the Internet, were studied. Russia has identified the priorities for the development of domestic software, including issues of its compatibility, and the requirements for its preferential use are being actively implemented.

Ensuring information security presupposes, first of all: a unified and stable information and telecommunications infrastructure; organizational and legal protection of the individual, organizations and the state, when using digital means; export of Russian technologies in the field of information security (but not their import).

\section{Conclusion}

An analysis of the acts of the President of the Russian Federation, the Government of the Russian Federation and national programs allows us to make an unambiguous conclusion that the state has not only set a grandiose task of digitalizing the economy, but also worked out a comprehensive system of measures to achieve it. Achievement of the national goal of digitalization of the economy will entail the creation of a new legal framework for relations between citizens, business and the state, which is bypassed (and even inevitable) due to the development of digital technologies of the economy; creation of a high-speed, high-tech and secure infrastructure for storage, processing and transmission of electronic data adequate to the needs of business and society; reforming the training system and saturating the labor market with qualified workers; as well as a comprehensive increase in the efficiency of public administration and the quality of the provision of public (municipal) services through the introduction of digital technologies and integrated solutions through state web platforms.

\section{Acknowledgment}

The article is prepared with the financial support of the Russian Federal Property Fund within the project No. 19-010-00886 (2018). The comprehensive economic and legal study of improving the competitiveness of the agro-industrial complex of the Russian Federation in the context of the development and integration of information-digital systems. 


\section{References}

1. A.P. Osipov, On the National Development Goals of Russia, 11, 45 (2020)

2. Galina Ivanovna Avtsinova, Olga Anatolyevna Blokhina, Natalia Vladimirovna Gubanova, Elena Evgenievna Konovalova, Julia Alexandrovna Semenova, Turismoestudos e praticas, 4, Sep (2020)

3. L.G. Akhmetshin, Economy, labor, management in agriculture, 8(53), 116 (2019)

4. M. Jawad, M. Naz, Z.Maroof, Business strategy and development, Sep (2020)

5. T. Kasimova, S. Magomedova, Z. Ismikhanov, J. of the knowledge economy, (2020)

6. E.R. Kokova, News of the Kabardino-Balkarian State Agrarian University named after V.I. V.M. Kokova, 3(21), 102 (2018)

7. Yongmin Chen, China economic review, 62, 101482, Aug (2020)

8. Natalya A. Yegina, Elena S. Zemskova, Natalya V. Anikina, Vladimir A. Gorin, Industrial engineering and management systems, 19(3), 576, Sep (2020)

9. A.M. Magomedov, Economy and management: problems, solutions, 1(12), 88 (2019)

10. G. Ganush, Proceedings of the national academy of sciences of belarus-agrarian series, 57(4), 418 (2019)

11. O.V. Ruzakova, E.V. Butsenko, A.V. Kurdyumov, Proceedings of the 33rd International Business Information Management Association Conference, IBIMA 2019: Education Excellence and Innovation Management through Vision 2020, 711 (2019)

12. A. N. Semin, D. A . Karkh, I. S. Kondratenko, Proceedings of the 1st International Scientific Conference on Modern Management Trends and the Digital Economy From Regional Development to Global Economic Growth (MTDE) AEBMRAdvances in Economics Business and Management Research, Apr 14-15, 81, 394 (2019)

13. N. N. Yurina, International Scientific and Practical Conference on Contemporary Issues of Economic Development of Russia - Challenges and Opportunities (CIEDR) European Proceedings of Social and Behavioral Sciences, Dec 12-13, NovSU Sch Econ \& Management, 59, 700 (2019) 